\title{
A arte de (sobre)viver coletivamente: estudando a identidade do Grupo Galpão
}

\author{
Mariana Mayumi Pereira de Souza \\ Alexandre de Pádua Carrieri
}

\begin{abstract}
O objetivo neste artigo foi analisar o processo de construção da identidade coletiva do Grupo Galpão, um grupo de atores de teatro fundado em 1982 e sediado em Belo Horizonte. O tema da identidade foi abordado em relação ao contexto da indústria cultural. Para o estudo da identidade, partiu-se do nível individual para entender significados coletivamente partilhados, notadamente em relação aos objetivos e à estrutura do grupo. Sendo a identidade individual construída a partir das práticas discursivas e sendo essas últimas sempre relacionadas a estruturas sociolinguísticas e aos gêneros discursivos, a identidade individual é revelada em determinado contexto e em relação a outras identidades, individuais e coletivas. Entende-se, na pesquisa aqui apresentada, que os espaços de interação delimitados pelas identidades coletivas fornecem limites para a expressão das identidades individuais. Entretanto, ocasionalmente, o indivíduo lograria transformar-se e transformar ativamente os espaços que lhe impõem relações de dominação. Para penetrar na realidade cotidiana do Grupo Galpão, foram realizadas observações e entrevistas em profundidade, as quais foram tratadas pela análise do discurso. Ao final da pesquisa, foram evidenciados aspectos identitários do Grupo Galpão que comprovam a estabilidade do grupo, mas que revelam tensões entre a racionalidade do mercado de bens culturais e a racionalidade intrínseca à produção artística autêntica.
\end{abstract}

Palavras-chave: identidade, prática discursiva, identidade coletiva, grupo de teatro.

\section{INTRODUÇÃO}

O objetivo neste trabalho foi a compreensão da dinâmica de construção de identidades no contexto de uma organização inserida no mercado de bens culturais, o Grupo Galpão. Entendido como locus de pesquisa, o Grupo Galpão é um grupo teatral composto por 13 atores sócios, fundado no ano de $1982 \mathrm{e}$
Recebido em 04/agosto/2010

Aprovado em 12/abril/2012

Sistema de Avaliação: Double Blind Review Editor Científico: Nicolau Reinhard

DOI: 10.5700/rausp1070

Mariana Mayumi Pereira de Souza, Graduada e Mestre em Administração pela Universidade Federal de Minas Gerais, é Doutoranda em Administração na Universidade Federal de Minas Gerais e Professora Assistente na Universidade Federal de Viçosa, Campus de Florestal (CEP 35690-000 - Florestal/MG, Brasil), e Membro do Núcleo de Estudos Organizacionais e Sociedade (NEOS).

E-mail: mayumi_mayumi@yahoo.com.br

Endereço:

Universidade Federal de Viçosa

Campus de Florestal

Rodovia LMG 818, km 06

35690-000 - Florestal - MG

Alexandre de Pádua Carrieri, Mestre em Administração pela Universidade Federal de Lavras, Doutor em Administração pela Universidade Federal de Minas Gerais, é Professor Titular da Universidade Federal de Minas Gerais (CEP 31270-901 - Belo Horizonte/MG, Brasil), Coordenador do Núcleo de Estudos Organizacionais e Sociedade (NEOS) e Pesquisador CNPq. E-mail: alexandre@face.ufmg.br 
sediado em Belo Horizonte. Com quase 30 anos de história, e sucesso reconhecido nacional e internacionalmente, o Galpão tem suas atividades sustentadas pelo patrocínio de empresas e pela venda de espetáculos. Em 1998, foi fundado o Galpão Cine Horto, um centro cultural em que se desenvolvem cursos e projetos variados. São empregadas cerca de 40 pessoas na estrutura total do grupo. A partir dessas características, acredita-se que a trajetória do Grupo Galpão ofereça um material rico para compreender como a identidade coletiva de um grupo artístico foi construída e reconstruída ao longo do tempo, com vistas a manter sua sobrevivência.

O Galpão surgiu a partir da associação de quatro atores, Teuda Bara, Eduardo Moreira, Wanda Fernandes e Antônio Edson. Eles conheceram-se em uma oficina de teatro oferecida por dois membros alemães do Teatro Livre de Munique, em Belo Horizonte, e, posteriormente, em Diamantina. Dos alemães, os fundadores do Galpão herdaram as influências do dramaturgo Bertolt Brecht, que tem sua obra reconhecida como politizada e contestadora. Além disso, o Grupo também herdou de seus mentores a tradição do teatro de rua, o trabalho circense e a sacralidade do teatro, como atividade digna de entrega e seriedade (BRANDÃO, 2002).

Desde sua fundação, alguns atores vieram a fazer parte do grupo momentaneamente, outros o integraram em definitivo. Dos 13 sócios atuais, três são fundadores e dez passaram a fazer parte do grupo a partir de aproximações profissionais e afetivas - há quatro casais no Grupo. Apesar do crescimento no número de membros, se comparado ao número inicial, pode-se considerar o Grupo Galpão um agrupamento estável, pois o último sócio a integrar o grupo o fez há mais de 17 anos.

A realidade social (e organizacional) recortada foi concebida como fruto da construção diária dos sujeitos, como participantes ativos e interpretadores do mundo que os cerca. Dessa forma, somente após certo tempo de convívio e de coleta de dados preliminares é que se tornou possível especificar parâmetros para o encaminhamento da pesquisa, que foi realizada por meio de observações não participantes e entrevistas semiestruturadas (BERGER e LUCKMAN, 1998).

Optou-se pelo conceito de identidade, pois ele abriria possibilidades de explorar a individualidade de cada sujeito no decorrer das interações sociais no grupo. A articulação das identidades individuais em níveis coletivos permitiria o entendimento dos significados coletivamente partilhados, das restrições que a identidade coletiva impõe à identidade individual e das razões que levam o sujeito a agrupar-se. Tais questões são consideradas centrais aos estudos organizacionais.

Os estudos sobre identidade nas organizações têm se destacado de forma crescente nas literaturas internacional e nacional. É possível distinguir pesquisas sobre identidade que partem de diversas linhas epistemológicas e abordam tanto o nível coletivo, da identidade corporativa e da imagem organizacional, como o caráter mais subjetivista, da identidade social e da identificação. Apesar da distinção clara entre as concep- ções, ressalta-se que, ao se tratar de identidade organizacional, acaba-se mencionando aspectos da identidade individual, o que demonstra certa complementaridade entre esses fenômenos (CALDAS e WOOD JR. 1997; BAUER e MESQUITA, 2007). No presente estudo, explorou-se a ligação entre os diversos níveis identitários possíveis dentro do ambiente organizacional, entendendo que as identidades individuais e coletivas são construídas de forma inter-relacionada.

Na pesquisa sobre o Grupo Galpão, o tema da identidade nas organizações aparece articulado à questão da produção artística contemporânea. Entende-se que o trabalho artístico organizado assume formatos diferenciados em relação às organizações econômicas. Isso porque se trata de um produto cuja natureza é altamente autoral e cujo valor assume sentidos simbólicos. A compreensão de como se inter-relacionam as identidades de artistas contemporâneos, principalmente quando se encontram agrupados de forma organizacional, pode gerar contribuições relevantes para estudos tanto no campo da identidade quanto no campo das organizações chamadas culturais ou criativas (GLYNN, 2000; BENDASOLLI et al., 2009).

No cenário atual da produção artística, observa-se, no Brasil e no mundo, a franca expansão do setor cutural, entendido como espaço de criação, consumo e geração de emprego (AVELAR, 2008). É notável o crescimento de investimentos financeiros nessa área e o número cada vez maior de pessoas que possui a arte como ocupação principal. Nesse processo, Avelar (2008) chama a atenção para a procura por profissionalização e formalização de uma gestão cultural.

O processo moderno de globalização e a crescente dinamização do chamado setor cultural têm reintroduzido o debate sobre a indústria cultural, cujo cerne estaria no fetichismo em relação aos bens culturais (DUARTE, 2002). O valor de uso desses bens, tradicionalmente representado pela admiração estética de um devir transcendente, passa a ser absorvido por seu valor de troca, advindo de uma valorização social artificial gerada pelo prestígio de consumir certo tipo de mercadoria cultural (HORKHEIMER e ADORNO, [1947] 2007).

A partir desse cenário, vislumbra-se uma tensão entre a criação de uma obra de arte autêntica e sua mercantilização, inerente à produção artística no contexto capitalista contemporâneo. Os dois processos envolvem práticas orientadas por racionalidades distintas, que culminam, por sua vez, em processos de construção identitária distintos. Reside nesse ponto o cerne do presente trabalho, em que se busca investigar como os membros de um grupo de teatro lidam com a construção da identidade coletiva ante os seus ideais éticos e estéticos, por um lado, e as pressões do mercado, por outro.

$\mathrm{O}$ presente artigo encontra-se estruturado em cinco partes, sendo a primeira esta introdução. Em seguida, serão apresentados os conceitos adotados a respeito da construção da identidade. $\mathrm{Na}$ terceira parte, são abordados os procedimentos metodológicos trilhados pela pesquisa. Na quarta e na quinta seções constam, respectivamente, a análise dos dados e as considerações finais. 


\section{PARA ALÉM DA DUALIDADE ENTRE IDENTIDADE PESSOAL E SOCIAL: ENTENDENDO A IDENTIDADE COMO PRÁTICA}

Estudos que abordam o tema da identidade partem, geralmente, da dualidade entre a perspectiva pessoal e a social. O conceito, nesse sentido, dividir-se-ia em dois: a identidade para si e a identidade para os outros (imagem) (CALDAS e WOOD JR., 1997). Contudo, neste trabalho, defende-se que é necessário que os estudos sobre identidade sustentem uma visão mais coerente e dinâmica, que considere tanto a importância da subjetividade quanto as determinações externas. A identidade seria um conceito dialético,

“[...] o resultado a um só tempo estável e provisório, individual e coletivo, subjetivo e objetivo, biográfico e estrutural, dos diversos processos de socialização que, conjuntamente, constroem os indivíduos e definem as instituições" (DUBAR, 2005, p.136).

Reforçando a ideia de que identidade-para-si e para o outro são construtos inseparáveis, como dois lados de uma mesma moeda, Ciampa (2005) propõe a concepção da identidade como a mesmidade de pensar e ser, ou seja, quando o indivíduo busca ser ele mesmo, não como forma de buscar sua essência, mas de ser ele mesmo como um ser que é determinado a partir da identidade. $\mathrm{O}$ autor, aludindo ao filósofo Heidegger, defende que o ser faz parte da identidade, e não o contrário: a identidade faria parte do ser.

Ciampa (2005) contrapõe-se à perspectiva da identidade como essência imutável do ser, pois, nessa visão, a identidade aparece como estática, concebida isoladamente, na condição de ser-para-si. Segundo Hall (2003), esse tipo de concepção essencialista é típico do período iluminista, no qual o pensamento predominantemente racionalista advogava que o ser humano deveria ser um centro dotado de razão e de consciência, sendo sua autoconcepção construída a partir de si mesmo, sem influência do mundo exterior. Dessa forma, a identidade torna-se um objeto misterioso e fantasmagórico, como um fetiche. Cria-se o que Ciampa (2005, p.146) denomina de

"identidade-mito, o mundo da mesmice (da não-mesmidade) e da má infinidade (a não superação das contradições)".

A ideia de identidade essencialista pode contribuir para reforçar a ideologia dominante, pois pode fazer com que as pessoas se deparem frequentemente com a necessidade de protelar transformações, evitar a evidência de mudanças, para que, de alguma forma, continuem sendo o que chegaram a ser em um momento de suas vidas e aceitem a manutenção de papéis sociais que muitas vezes lhes foram impostos.
Segundo Arendt (2004), o homem distingue-se dos demais a partir do momento em que inicia sua atividade no mundo. Agindo, os seres humanos manifestam-se uns aos outros e, somente assim, assumem a condição humana, tornam-se algo além de meros objetos físicos e vão além da mera existência corpórea. O homem é o único ser capaz de exprimir o que o diferencia dos demais, de estabelecer distinção das outras pessoas. Só ele é capaz de comunicar a si próprio. A revelação de alguém estaria implícita tanto em suas palavras quanto em seus atos.

Para Arendt (2004), mesmo quando as palavras e os atos estão voltados para questões instrumentais do mundo objetivo, eles ainda conservam a capacidade de revelar o agente por trás. Notadamente na expressiva maioria dos casos, palavras e atos referem-se à mediação entre os homems e seus interesses específicos relacionados ao mundo. $\mathrm{O}$ agente que fala e age revela-se no momento em que estabelece relação com a realidade mundana e objetiva.

Ciampa (2005) nota a dificuldade de caracterizar alguém somente por meio de verbos, sem o uso de substantivos e adjetivos. Contudo, ao substantivar o indivíduo no discurso, cria-se a ilusão de uma substância de que ele seria dotado e que se expressaria através dele. No momento em que se tenta definir quem alguém é, constrói-se um personagem com as características que a pessoa partilha com outras que lhe são semelhantes. Nesse processo, perde-se de vista o que cada indivíduo possui de singular e específico. Não se diz quem a pessoa é, mas o que ela é. Ao solidificar-se em palavras a essência viva de alguém, essência que é fluida, corre-se o risco de tratar identidades como coisas cuja natureza se pode dispor e nomear (ARENDT, 2004).

Para Ciampa (2005), conforme já exposto, as identidades pressupostas, tidas como algo dado, contribuem para a manutenção do sistema da forma como ele está, sendo cada um responsável por manter sua identidade, por ser coerente com as expectativas alheias. Não se pode retirar o caráter de historicidade da identidade, pois, dessa forma, ela aproxima-se mais da noção de um mito, que prescreve as condutas corretas e reproduz o mundo social. Nesse sentido, é crucial conceber a identidade como um processo que emerge como a história singular de uma vida. A construção da identidade teria seu fim somente com a morte, quando o indivíduo para de manifestar-se como sujeito (ARENDT, 2004).

A emergência de uma história de vida singular ocorre necessariamente em interação mútua com outras histórias de vida. A construção de cada identidade incide em uma teia de relações já existentes e nela imprime suas consequências imediatas. A história produz-se, intencionalmente ou não, graças à interação nesse meio (ARENDT, 2004). A partir disso, estabelece-se uma rede de reflexões, em que as identidades se refletem e se reforçam, por meio de representações (CIAMPA, 2005).

"Esse jogo de reflexões múltiplas que estrutura as relações sociais é mantido pela atividade dos 
indivíduos, de tal forma que é lícito dizer-se que as identidades, no seu conjunto, refletem a estrutura social, ao mesmo tempo que reagem sobre ela, conservando-a (ou transformando-a)" (CIAMPA, 2005, p.171).

Nesse sentido, a atividade humana no mundo pressupõe posicionamento e revelação.

"Eliminar essa revelação - se isso de fato fosse possível - significaria transformar os homens em algo que eles não são; por outro lado, negar que ela é real e tem consequências próprias seria simplesmente irrealista" (ARENDT, 2004, p.196).

Destaca-se a inevitabilidade com que os homens se revelam como sujeitos, como pessoas distintas e singulares, mesmo quando interagem instrumentalmente, assumem papéis sociais impostos, de forma a alcançar objetivos materiais e mundanos e quando corroboram a estrutura das relações sociais.

Estudar a identidade como representação é entendê-la como produção, pois o indivíduo não é exatamente algo, mas sim o que ele faz. Sendo o fazer sempre atividade no mundo, em relação com os outros, o pesquisar sobre identidade desloca-se de uma questão meramente descritiva para a questão "de compreensão, de entendimento", sendo necessário "captar os significados implícitos, considerar o jogo das aparências. A preocupação é com o que se mostra velado" (CIAMPA, 2005, p.139).

Se a identidade se encontra expressa basicamente quando o indivíduo interage direta ou indiretamente com o outro, somente a partir da ação no mundo é que o indíviduo se posiciona e manifesta quem ele é em sua essência (ARENDT, 2004). Em um contexto de relações de poder, tais movimentos interativos são mais bem compreendidos por meio da análise do posicionamento assumido, que pode ser estratégico ou tático. Para os dominados, isso significa assumir uma posição de resignação ou de resistência (CERTEAU, 1994). Ademais, tal posicionamento necessariamente se encontra orientado por uma racionalidade. Quando se age de acordo com valores éticos e estéticos, construir-se-ia uma identidade substantiva. Por outro lado, quando se age de acordo com fins calculados, construir-se-ia uma identidade instrumental (RAMOS, 1981; MANNHEIM, 1986).

Para a interpretação dos sentidos e racionalidades expressos nas manifestações identitárias, é inevitável sua transposição para o nível discursivo. Arendt (2004) defende que a ação desprovida da esfera discursiva não é ação propriamente dita, pois não revela seu ator e não permite sua manifestação interativa. Para a análise da identidade, toda prática passa por sua dimensão discursiva - mesmo as práticas não verbais seriam transpostas ao nível discursivo, ou semiotizadas, para que o pesquisador possa desvendar seu significado e a identidade de seu ator (FAIRCLOUGH, 2003; FOUCAULT, 2007).
A partir das conceituações expostas, propõe-se neste trabalho que estudos sobre identidade perpassem a análise das práticas dos sujeitos. Tais práticas revelariam identidades ao serem apreendidas por meio da semiotização, ou seja, da interpretação dos sentidos de quem agiu. Mesmo que a ação em análise não seja verbal, leva-se também em consideração o discurso não verbal do indivíduo. Trata-se, dessa forma, de uma tríade de dimensões inseparáveis (identidade - prática discurso). É necessário reconhecer, no entanto, que o processo de interpretação dessas dimensões será sempre falho, pois está atrelado à interpretação de um agente exterior, nesse caso do pesquisador. O pesquisador nunca será capaz de desvendar inteiramente a construção de sentidos do indivíduo no momento em que ele age e, assim, também não é capaz de apreender integralmente qual seria sua identidade. No processo de análise discursiva/semiótica, o pesquisador irá apreender parcialmente os sentidos e a interpretação deles sofrerá interferências de sua subjetividade.

\section{CAMINHOS METODOLÓGICOS: INTEGRANDO O CONCEITO DE IDENTIDADE À ANÁLISE DO DISCURSO}

Tendo consciência das limitações epistemológicas inerentes à abordagem qualitativa, neste estudo a pesquisadora buscou aproximar-se da realidade dos sujeitos pesquisados por meio de entrevistas complementadas por observações. Ademais, buscou-se restringir a análise das identidades, considerando somente o agir no espaço (físico e simbólico) do Grupo Galpão e dando ênfase à relação da identidade individual com a construção da identidade coletiva.

Sendo a identidade individual construída a partir das práticas discursivas e sendo essas últimas sempre relacionadas às estruturas sociolinguísticas e aos gêneros discursivos, a identidade individual é revelada em determinado contexto e em relação a outras identidades, individuais e coletivas. Entende-se nesta pesquisa, portanto, que as identidades coletivas seriam espaços em que predominam certos gêneros de discurso, certos padrões de práticas enunciativas (BAKHTIN, 1992). Inserido em uma identidade coletiva, o indivíduo compartilha com os demais determinados significados, racionalidades e práticas, que fundamentariam, em última instância, a própria razão de existência do grupo. A figura da página 11 ilustra o entendimento das relações entre os níveis individual e coletivo da identidade. Tal entendimento orientou as análises dos dados coletados.

Dessa forma, buscou-se primeiramente diferenciar os elementos discursivos pertencentes aos indivíduos e os elementos compartilhados, pertencentes às identidades coletivas. Em seguida, analisaram-se os discursos de forma a desvendar os aspectos ideológicos que os permeavam, tanto dos indivíduos quanto dos coletivos. A partir disso, foi possível delinear as identidades construídas no interior do Galpão, assim como as tensões entre racionalidades e identidades individuais e cole- 


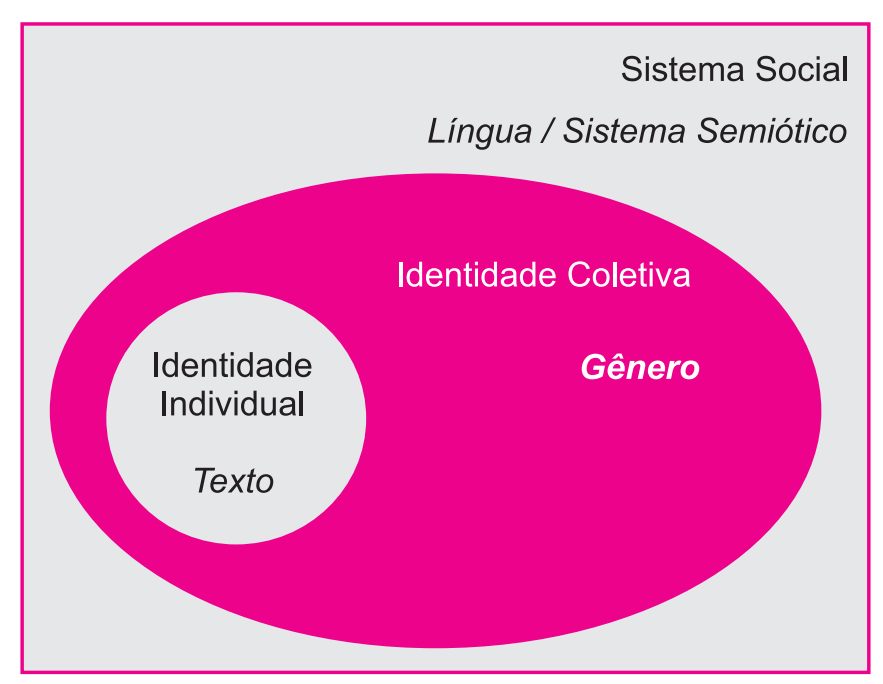

\section{Articulação entre os Níveis Identitários e} Discursivos

tivas. Em suma, entende-se, nesta pesquisa, que os espaços de interação delimitados pelas identidades coletivas fornecem limites para expressão das identidades individuais. Entretanto, o indivíduo teria oportunidades de escolha quanto às identidades coletivas das quais faria parte. Ademais, ocasionalmente, o indivíduo poderia também transformar ativamente os espaços que lhe impõem relações de dominação (RAMOS, 1981; CIAMPA, 2005).

Para penetrar na realidade cotidiana do Grupo Galpão, a pesquisadora realizou um trabalho de coleta de dados que perdurou por cerca de 12 meses. A pesquisa de campo pôde ser dividida em três etapas. Na primeira, que representou os primeiros oito meses de pesquisa, foram coletados dados documentais e bibliográficos preliminares sobre o Grupo Galpão. Houve também conversas informais com pessoas ligadas ao grupo, como amigos e familiares. Ademais, a pesquisadora frequentou o primeiro módulo do Curso Livre de Teatro oferecido pelo Galpão Cine Horto. Os primeiros contatos foram, portanto, observações assistemáticas, registradas em diários de campo.

Em seguida, partiu-se para a segunda etapa da coleta de dados, que envolveu observações não participantes e entrevistas em profundidade. Em meados de maio de 2009, a pesquisadora iniciou o acompanhamento dos ensaios de montagem da peça "Till: a saga de um herói torto", do Grupo Galpão. Os ensaios ocorriam de segunda a sexta, das $14 \mathrm{~h} 30$ às $20 \mathrm{~h} 00$, na sede do Galpão. As observações foram feitas até o final do mês de junho e também em três espetáculos de estreia. Em seguida, durante os meses de julho e agosto, foram entrevistados onze atores do Galpão. Posteriormente, as entrevistas foram transcritas e o diário de campo relido.

A partir disso, passou-se para a terceira etapa: a análise dos dados. A análise ocorreu conforme os elementos teóricos e metodológicos delimitados, seguindo as definições dos con- ceitos e a Análise do Discurso (AD). Buscou-se evidenciar textualmente os seguintes elementos: percursos semânticos; significados implícitos da semântica e da sintaxe; relações interdiscursivas; e quatro estratégias de persuasão - criação de personagens, relação entre temas explícitos e implícitos, silenciamento e seleção lexical (FARIA e LINHARES, 1993; MAINGUENEAU, 2000).

Neste texto, especificamente, optou-se por apresentar as análises referentes aos temas contidos no percurso semântico sobre os objetivos do grupo, pois ele foi o mais revelador da dinâmica de construção da identidade coletiva. Ao longo da exposição das análises, utilizou-se a reprodução de trechos originais das falas dos entrevistados, com vistas a conferir maior transparência aos processos interpretativos realizados. Os trechos reproduzidos são sempre identificados pelos seus enunciadores, cujos nomes foram mantidos em sigilo. Os onze entrevistados do Grupo Galpão estão representados pela sigla GG e seus respectivos números. São destacadas em negrito as expressões que mereceram destaque nas análises.

\section{O GRUPO GALPÃO: A ARTE DE (SOBRE)VIVER COLETIVAMENTE}

Conforme já exposto, o Grupo Galpão surgiu com influências de um fazer teatral politizado, a partir das ideias de Bertolt Brecht, o que demarca um aspecto importante para a construção da identidade coletiva do grupo. Ao longo de sua trajetória, em contrapartida, observa-se que o Galpão logrou firmar-se no cenário artístico a partir do recebimento de patrocínios e venda de espetáculos. Por meio das análises a seguir, buscou-se clarear as formas como o grupo estabelece objetivos e se organiza coletivamente para conciliar seus ideais éticos e estéticos com as pressões do mercado de bens culturais. Acredita-se que tal tensão sirva de fio condutor para compreender a construção identitária do grupo.

\subsection{A gênese do grupo como estratégia de sobrevivência coletiva}

Com vistas a desvendar sentidos sobre a identidade coletiva do Grupo Galpão, conforme já exposto, evidenciou-se aqui o percurso semântico sobre os objetivos do grupo. O tema que dá início a esse percurso semântico é o da gênese do grupo.

"E aí a gente enfim encarou a vida como... apostando no grupo como assim profissão, como sustentação, como um projeto mais a médio e longo prazo com uma estrutura melhor" (GG1).

"Claro que, quando nós pensamos montar um grupo, dar sequência a esse trabalho com os alemães, a gente tinha essa ideia de ser um grupo, né? De criar uma linguagem, de ter uma proposta a... 
a... a médio e longo prazo. Não ser uma coisa imediata" (GG9).

"Investimento no ator mesmo com aulas e o Galpão sempre teve isso, né. Antigamente vivia precariamente, mas ele era um grupo que ficava ali pesquisando" (GG11).

Destaca-se, primeiramente, que o tema da gênese do grupo é permeado pela dimensão temporal do longo prazo. Os enunciadores representam a origem do Galpão como um momento em que os membros vislumbraram obter resultados futuros por meio da ação coletiva. Nesse sentido, trata-se de práticas do tipo estratégias, segundo Certeau (1994). A institucionalização de um grupo, como espaço legítimo de união de esforços individuais, seria uma forma de viabilizar o cumprimento da estratégia coletiva. Os vocábulos utilizados para denotar tal processo de institucionalização nesses trechos são: grupo, projeto, estrutura, linguagem, proposta. Esse seria o espaço a ser chamado de próprio e onde no decorrer dos anos seria exercido o poder estratégico em prol do atingimento dos objetivos. Ademais, os verbos apostar e investir trazem implícita a ideia de acúmulo futuro, típica da ação estratégica.

Um dos objetivos iniciais do grupo teria sido viabilizar a sobrevivência por meio do trabalho com o teatro.

"Isso... isso era muito claro pra nós. Que era importante que cada um pudesse tirar o sustento do próprio trabalho do grupo. A gente se... a gente percebia que sem isso a gente não ia poder seguir em frente, né? Por que um trabalho que não gera o seu sustento é um trabalho condenado ao seu fracasso, né?" (GG9).

"Mas eu percebi, eu percebo, que a primeira intenção do coletivo, de montar um grupo, era de ser uma coisa profissional, uma coisa que tivesse uma... horário, uma técnica qualquer de fazer espetáculo..." (GG2).

"Eu acho que uma maneira, uma seriedade muito grande, um compromisso muito grande com o trabalho, com a qualidade do trabalho... com a maneira de fazer e um comprometimento muito grande com isso, né... e... com a perspectiva de transformar aquilo num modo de vida" (GG3).

Nos trechos destacados está explícito o objetivo de obter, a partir do trabalho em grupo, uma forma de manutenção da existência. GG9 coloca a ideia da sobrevivência a partir do teatro como condição para o sucesso e a continuidade do próprio grupo. Como o relato foi coletado no final de 2009 , o enunciador deixa implícita a ideia de que o grupo é bem- -sucedido, já que logrou sustentar-se por tantos anos. GG2 retoma o tema do profissionalismo, relacionando-o à existência de normas e práticas compartilhadas. Infere-se que, somente por meio do agrupamento de atores, é que seria possível obter tal estruturação do trabalho. GG3 também representa a existência do grupo como uma forma de estruturar maneiras de fazer e práticas voltadas ao resultado final dos esforços, que deveria ser de boa qualidade e prover a sobrevivência. Nesse sentido, a representação do grupo como uma instância provedora de manutenção da existência de seus membros traz implícita a ideia de que o grupo deveria ser a instância central de identificação desses indivíduos. Ao almejar que todos os membros pudessem dedicar-se integralmente ao trabalho em grupo, como atividade principal, infere-se o objetivo coletivo de que suas identidades estivessem vinculadas primariamente ao Galpão e não a outras atividades instrumentais que gerassem sustento.

\subsection{A ocupação da rua como estratégia identitária}

O tema da ocupação da rua é representado como uma tática vislumbrada pelo grupo, desde sua gênese, para contornar de forma astuciosa as relações de poder dominantes no contexto de produção teatral. A caracterização do teatro de rua inicialmente como tática se baseia na ideia de que o grupo, ao se apresentar nas ruas, buscava retorno imediato e oportunista, apropriando-se de um espaço que não the era próprio (CERTEAU, 1994).

"Do artista ir aonde o povo está, o Galpão sempre fez isso... desde quando começou e não como uma coisa demagoga, assim neste sentido: 'Ah, precisamos levar cultura ao povo!' Mas até como estratégia de sobrevivência, né?" (GG4).

"Foi um dos motivos que o Galpão apareceu na rua, pra não depender de espaços públicos, os espaços eram todos públicos, da prefeitura, do estado e era uma dificuldade terrível" (GG11).

"A opção do Galpão de ter a rua foi o grande diferencial para conquistar os patrocinadores, conquistar o público, porque... dentro das salas de teatro a gente vê... o público é muito pouco, né?" (GG2).

A prática de levar o teatro para a rua é representada como uma opção criativa e de resistência para garantir a sobrevivência nos primórdios do grupo, a independência dos controladores dos espaços públicos (prefeitura e estado) e a atração dos personagens patrocinadores e público.

A tática do teatro de rua, ao tornar-se bem-sucedida e reforçar-se ao longo dos anos, torna-se um dos elementos identitários centrais do Grupo Galpão, integrando o objetivo estratégico coletivo de gerar o sustento por meio do teatro. 
Nesse sentido, a partir de uma tática de resistência ao poder controlador das casas públicas de teatro, a estratégia do Grupo Galpão constrói-se e, aos poucos, o espaço da rua passa a ser apropriado e, até mesmo, tornado um espaço legítimo do Galpão, sendo reconhecido pelo público como tal. Portanto, trata-se de uma prática que surge inicialmente como tática e, posteriormente, torna-se uma estratégia identitária.

"O grupo já é muito conhecido com teatro de rua e tudo, tinha uma necessidade. O público também pedia que a gente voltasse pra rua" (GG5).

"Vai estabelecendo uma... uma maneira, um jeito de fazer, você vai imprimindo aquilo. Então, se de repente o Galpão resolve: 'Ah não, o próximo espetáculo do Galpão vai ser um espetáculo aos moldes da A Comédia da Esposa Muda', que a gente fazia com condições favoráveis de alojamento para o público, a gente fazia para, no máximo, no máximo 500,600 pessoas e o que... aí você fica meio refém da sua, da sua... acaba que o Galpão, neste sentido, fica um refém da popularidade dele" (GG3).

"A história do Galpão tem muito dessa... dessa coisa de... de ocupar pela primeira vez o espaço, a gente fez o primeiro espetáculo na Praça do Correio no Rio, que depois virou espaço para espetáculo, fez no Ipiranga em São Paulo que também virou espaço para espetáculo, fez na Praça JK antes dessa reforma que você conhece, fez, usou pelo FIT a primeira apresentação lá na Serraria Souza Pinto" (GG1).

"Começou com essa coisa da rua, né?, de entrar na vida, de entrar, de ocupar, de ocupar o seu lugar, de ir se aprimorando e ocupando o seu lugar, depois também não quis ficar... logo no início, começou já a fazer teatro de sala também" (GG7).

Os trechos destacados trazem em comum o tema implícito da legitimidade do Galpão como grupo de teatro de rua. À personagem público é atribuída a responsabilidade do reconhecimento do trabalho do Galpão. GG5 representa o público como uma figura que demanda peças de rua. Nesse sentido, atender a tal expectativa é uma estratégia de manutenção identitária do grupo. GG3, por meio do verbo no gerúndio imprimir, também sugere implicitamente a ideia de que, ao longo do tempo, o Galpão construiu sua identidade calcada no teatro de rua. Contudo, o enunciador representa o lado negativo do reconhecimento do público, pois, passados quase 30 anos de sua fundação, o grupo não teria mais a liberdade de realizar peças de rua nos moldes de suas peças iniciais. A partir do adjetivo refém, infere-se que, segundo o enunciador, o Galpão teria um número restrito de práticas possíveis, sendo sua identidade também limitada ao que o próprio grupo reforçou durante anos. Nesse sentido, sinaliza-se a dificuldade de empreender uma identidade coletiva do tipo metamorfose para o Galpão, devido às pressões e expectativas de agentes externos que o grupo precisa atender (CIAMPA, 2005). Manter uma identidade de refém, portanto, seria praticar uma identidade instrumental.

Por outro lado, GG1 e GG7 reforçam a ideia de que o Galpão, aos poucos, se apropriou do espaço da rua como lugar próprio. O uso do verbo ocupar traz implícita tal ideia. Nesse sentido, o grupo teria liberdade para ocupar legitimamente diferentes lugares nunca antes utilizados por outros grupos de teatro. Tal prática, segundo GG1, teria constituído um traço identitário para o grupo. GG7 enfatiza a prática do grupo de conciliar o teatro de sala com o teatro de rua desde o início. Em outras palavras, tratar-se-ia de uma estratégia de variação das práticas para, talvez, evitar que o grupo se tornasse refém da própria identidade, como exposto por GG3.

"A gente procura ir em lugares onde o teatro não vai, né?... e realmente é uma delícia você desvirginar esses lugares, sabe? Então, eu acho que essa, pra mim, é a grande importância do Galpão na sociedade. É ir chegando e desbravando, o que é um pouco bandeirante neste sentido" (GG4).

"Eu acho que a gente fazendo teatro de rua, a gente tá fazendo mais uma condição social do que teatro de palco" (GG2).

"O próprio fato da gente fazer teatro na rua, eu acho que, quando a gente vai pra uma praça onde não interessa, todo mundo pode ir, não interessa de onde, quem, todo mundo está ali assistindo. Em alguém ali a gente vai despertar alguma coisa nova, com certeza. A gente tem tido o retorno disso. Estar na rua acho que também é um projeto social. A gente proporciona uma experiência estética, mesmo reflexiva, através da gargalhada você pode tocar outras coisas também" (GG6).

Além de tática de sobrevivência e estratégia identitária instrumental, o tema do teatro de rua também é representado pelo sentido ético, o que constrói sentidos substantivos à identificação do grupo com o trabalho na rua. Levar o teatro a lugares inusitados e a pessoas que não costumam frequentar as casas de espetáculos é destacado como uma prática boa e desejável. GG4 compara metaforicamente o Galpão à figura de um "bandeirante, que desvirgina, chega e desbrava" lugares aonde o teatro ainda não foi. Tal metáfora traçaria um paralelo entre a função colonizadora dos bandeirantes e a função cultural do Galpão, cuja atuação na sociedade seria a disseminação de valores culturais. Nesse ponto, observa-se uma relação interdiscursiva com o discurso da cultura afirmativa, o que possibilita 
o questionamento da existência de valores éticos autênticos, pois o sentido implícito estaria mais próximo aos valores morais instrumentais, suavizantes de conflitos sociais e homogeneizantes (MANNHEIM, 1986; MARCUSE, [1937] 2001).

GG2 compara as duas formas de teatro, de rua e de palco, e representa a primeira como mais próxima à atuação social. O enunciador silencia, contudo, sobre qual seria o conteúdo de tal atuação. GG6, por sua vez, representa implicitamente a prática do Galpão, de levar o teatro de rua a locais que não interessam, como calcada em valores éticos. Primeiramente, pelo fato de serem lugares onde financeiramente não seria interessante apresentar-se. Em segundo lugar, pelo fato de a prática do teatro de rua proporcionar experiência estética às pessoas. Tal tipo de experiência estaria ligada a momentos de reflexão. Infere-se que poder tocar os espectadores é considerado bom e desejável pelo enunciador. Nesse sentido, a arte é representada como forma de proporcionar experiências transcendentes às pessoas que assistem a ela, não apenas ao artista que a realiza. Nesse trecho, destaca-se ainda o uso do vocábulo praça, como aparece outras vezes no depoimento de outros membros, não em seu sentido literal, mas para denotar lugar de atuação. O uso da palavra praça dessa forma traça uma relação interdiscusiva com o vocabulário da administração estratégica, como local de exploração comercial e apropriado como espaço de competição entre organizações. Portanto, coexistem no discurso elementos semânticos ligados à ética e à instrumentalidade capitalista. Nota-se que a ambiguidade é um figura semântica recorrente nos depoimentos.

"É nossa grande dificuldade, às vezes maior, é isso: é uma empresa que não é uma empresa com fins lucrativos. Nós somos sócios, mas a gente não tem uma visão empresarial de enriquecer, então é uma empresa peculiar, assim, estranha, nesse sentido [...] apesar da gente sobreviver do dinheiro que ela gera, mas a gente não visa o lucro" (GG5).

"A gente não construiu a Associação Galpão pra ficar rico com o teatro. Isso seria uma ilusão muito grande, mas tem sempre esse sentido artístico dali, do grupo, né?, que é decidido sempre... as decisões artísticas são feitas em grupo, né?, numa reunião com os 13" (GG4).

"Bem no começo, o Galpão procurava dinheiro, não para, pra fazer uma peça. Não, se procurava, procurava dinheiro pra bancar um projeto de um ano, que fosse. Um projeto esse que iria incluir uma série de, uma série de outras coisas [...] um tanto de coisas enriquecedoras" (GG7).

Nesses trechos, observa-se a presença de sentidos ambíguos implícitos ligados aos objetivos do Grupo Galpão.
O fato de os membros terem constituído o grupo ou terem aceitado fazer parte dele, com o intuito de que o Galpão fosse a instância provedora central de realização artística e de sobrevivência financeira, leva à inserção do grupo no mercado de bens culturais e, ao mesmo tempo, à busca da manutenção da criatividade e dos objetivos éticos. Muitas vezes, essa dupla consequência gera ambiguidades nas práticas discursivas sustentadas pelo grupo. GG5, ao caracterizar o Galpão, utiliza o vocábulo empresa, que denota um tipo de organização com fins lucrativos, mas nega imediatamente a busca do lucro e reconhece explicitamente a construção paradoxal, por meio dos vocábulos peculiar e estranha. GG4 sugere explicitamente a predominância do sentido artístico da existência do grupo sobre o sentido financeiro. Contudo, ao citar ambos, faz pressupr sua coexistência nas atividades coletivas. GG7, por sua vez, conta que, desde o início, o objetivo do Galpão não era a busca de financiamento para a produção de peças teatrais, mas sim para a manutenção de uma série de atividades extra-artísticas desenvolvidas pelo grupo, consideradas enriquecedoras. Nesse sentido, o enunciador deixa implícito que o sentido ético da atuação do Galpão se sobreporia à própria atividade artística em si, negando-se a busca de dinheiro sem tal sentido. Contudo, novamente se observa a menção às esferas financeira, artística e ética no discurso, o que sinaliza para a coexistência dessas esferas, e de suas distintas racionalidades, na própria prática cotidiana do grupo.

\subsection{O Galpão Cine Horto e as transformações identitárias}

Ao longo das narrativas sobre a trajetória do Grupo Galpão, surgem novos sentidos e temas ligados aos objetivos coletivos. O Galpão Cine Horto, centro cultural fundado pelo grupo, é uma figura discursiva relevante, que sinaliza para novos sentidos atribuídos à identidade do grupo.

"Eu acho que o grupo continua fiel a esse propósito inicial. É... é claro que isso foi se modificando, né? É... acho que em muitos aspectos o grupo se tornou mais flexível, existe a coisa do centro cultural, existe uma preocupação, assim de uma transmissão também de conhecimento, né?" (GG9).

"Mas eu achava que o Galpão não... que devia... devia orientar fogo, no outro sentido, num sentido mais meramente artístico... mas acho que foi uma grande ideia, acho que é um projeto maravilhoso, que dá a oportunidade ao Galpão de prestar um serviço, né?" (GG3).

Tanto GG9 quanto GG3 são membros fundadores do Grupo Galpão. Portanto, já faziam parte do grupo quando foram estabelecidos seus objetivos originais. Talvez não seja mera coincidência o fato de que ambos os enunciadores atribuem à 
figura do Cine Horto, implícita nas expressões centro cultural e projeto, uma mudança nos propósitos iniciais do Galpão. Tal mudança seria um aumento no escopo de atuação do grupo, ideia implícita nos vocábulos flexível e grande ideia. A partir de tais expressões, infere-se que o coletivo possuía objetivos centrais determinados e acabou admitindo objetivos novos com o passar do tempo. A identidade coletiva do Galpão adquiriu novos sentidos, a partir de novas estratégias e novas práticas, saindo do meramente artístico para a transmissão de conhecimento e a prestação de serviço.

Ademais, GG3 admite explicitamente sua resistência inicial ao aumento do escopo de atividades do grupo. Contudo, fica implícito que decisões foram tomadas, mesmo havendo sua discordância inicial, no sentido da implementação do projeto do Cine Horto. Observa-se, portanto, no discurso de GG3, que a representação da identidade coletiva do Galpão sofreu alteração, de um grupo voltado à prática da arte, para um que também presta serviços. Essa alteração, no entanto, parece ter sido posteriormente bem aceita pelo enunciador, sentido implícito nos adjetivos grande e maravilhoso. Assim, infere-se que não houve rompimento identificatório por parte de GG3 em relação ao Galpão. O enunciador continua fazendo parte do grupo e, agora, aceita todos os objetivos coletivos.

Ao contrário de GG3 e GG9, alguns membros do Galpão representam a criação do Cine Horto como uma prática natural, decorrente dos propósitos originais do grupo.

"O Cine Horto faz com que o grupo não se feche. Na verdade o Galpão nunca se fechou, ele já criou o FIT, Festival de Teatro de Rua. Então, o Galpão sempre compartilhou muito com outros artistas e o Cine Horto ampliou isso" (GG5).

"Ficou um vácuo nessa relação do Galpão, nossa com a sociedade, já que a gente não fazia mais o FIT. Foi aí que aparece o Cine Horto, a possibilidade do Cine Horto" (GG1).

GG5 e GG1 representam o Galpão como um grupo que possui vocação desde sempre para relacionar-se com a sociedade. GG5 deixa essa ideia explícita nos advérbios nunca e sempre. Nesses trechos, a figura explícita do Cine Horto é representada como uma estratégia de manutenção identitária do grupo, no sentido de manter a prática de interlocução com indivíduos externos. O FIT teria sido também uma estratégia dessa natureza, contudo foi abandonada pelo grupo. Observa-se, em ambos os relatos, que os enunciadores empregam sentidos de modalidade em relação ao tema da interlocução com a sociedade, ou seja, eles o representam como um sentido a priori, verdadeiro e necessário, sendo justificativa válida para a criação do Cine Horto. Portanto, é necessário que haja tal preocupação extra-artística por parte do grupo. Caso contrário, conforme exposto por GG1, haverá um vácuo.
"Acho o Cine Horto um projeto muito bacana e ele... ele... Além da beleza do projeto em si, ele é muito legal também por causa da demanda, porque o Galpão viaja muito e tem muita gente que quer ter experiências próximas ao Galpão, entendeu?" (GG6).

"Essencial pro Galpão, porque o Cine Horto é... cobre uma demanda enorme de pessoas que querem trabalhar com o Galpão, que querem conhecer, ficar mais próximo do Galpão, né. Além de ter uma... como é que fala? Uma vertente voltada para o social, pra comunidade e que é muito importante pro grupo também, né? Além de tudo, possibilitar mais janelas pra arejar mais a gente aqui dentro" (GG10).

"A gente não tá aqui todos os dias, e quem toca realmente são essas pessoas que vieram aqui buscar o conhecimento, reciclagem e vem com ideias também que a gente acaba descobrindo. Eu acho que é isso que faz essa dinâmica tão bacana do Cine Horto, então eu acho que essa é a nossa maior contribuição, não fechar, né, mostrar sempre, procurar mostrar sempre que é possível ir um pouco além...” (GG4).

Além de estratégia de flexibilização ou de manutenção identitária, o Cine Horto também é representado como uma estratégia de extensão identitária. Nos três trechos acima destacados, o Cine Horto é representado como um território do Grupo Galpão, que o representa mesmo quando seus membros não estão presentes. Nesse sentido, o Cine Horto seria uma estratégia do Galpão que permite a desvinculação da identidade do grupo das identidades individuais de seus membros. O Galpão passaria a ser representado como uma entidade que engloba não só o grupo de atores, mas também a estrutura do Cine Horto e as pessoas que dele fazem parte. Nos trechos destacados, de GG6 e GG10, observa-se o duplo sentido que o vocábulo Galpão assume, tanto como grupo de atores, nas expressões Galpão viaja e essencial pro Galpão, quanto como como entidade que pode ser legitimamente representada pela figura do Cine Horto, na expressão próximo ao Galpão.

Embora a criação do Cine Horto denote um movimento de extensão da identidade do Galpão, observa-se que o duplo sentido do vocábulo Galpão se mantém ao longo dos discursos, sinalizando que há diferenças entre a identidade do grupo de atores e a identidade da entidade Galpão. GG10 deixa explícita a existência dos limites entre as duas identidades, ao dizer a gente aqui dentro para referir-se aos atores do Galpão em relação às possibilidades de interação com o Cine Horto. GG4 também explicita a diferenciação entre a gente, atores do Galpão, e as pessoas que trabalham no Cine Horto. Nota-se que, a partir do tema do surgimento do Cine Horto, todos os enunciadores passam a denotar a diferenciação identitária entre 
o Galpão, como grupo de atores, e o Galpão, como entidade. Tal diferenciação é muitas vezes tênue e não explícita, mas recorrentemente se torna clara.

"Então, ela (empresa patrocinadora) tem uma... um ganho aí, da marca associada ao Cine Horto. Que por tabela tá associado ao Galpão e o Galpão também, por tabela tá associado ao Cine Horto, né? Então todo esse trabalho social que o Cine Horto faz e... e ele reverte também numa... numa boa impressão que a população tem do Galpão" (GG11).

"Embora a Petrobras patrocine aqui, mas nos olhos da mídia, nos olhos da opinião pública, nos olhos institucionais, assim, o Galpão desenvolve uma dezena de projetos de formação, de troca, de pesquisa, de produção através do Cine Horto. Então o Cine Horto é meio que... ajuda na imagem, sabe, ele justifica um pouco algumas coisas que a gente tem" (GG1).

"Eu acho que é porque ele complementa um lado social que o Galpão não dá... Não consegue dar porque a gente fica na coisa do espetáculo, de representar, a gente dá oficina quando a gente viaja [...]. Mas é o máximo que a gente consegue dar e o retorno que o Cine Horto dá é importantíssimo pra gente. [...] O Galpão Cine Horto é totalmente, é um peso na balança assim, que é importantíssimo. Então é uma moeda bem valiosa" (GG2).

Por fim, a quarta representação da figura do Galpão Cine Horto é de uma estratégia de projeção identitária perante a sociedade e os patrocinadores. Os projetos realizados no Cine Horto serviriam para projetar uma identidade positiva do Grupo Galpão. Tal identidade, contudo, assume implicitamente sentidos instrumentais e artificiais. Tais sentidos são inferidos a partir das expressões boa impressão, imagem, peso na balança e moeda valiosa. Novamente, encontra-se implícita a diferenciação entre a identidade do Galpão (grupo de atores) e a identidade do Galpão Entidade (entidade que engloba os atores e o Cine Horto). Nos três trechos destacados, os enunciadores colocam-se explicitamente cientes de que, aos olhos de personagens externos (empresas, sociedade, instituições), as identidades do Grupo Galpão e do Galpão Entidade misturam-se.

A manutenção de uma identidade única, englobando grupo de atores e Cine Horto, seria uma estratégia interessante para os enunciadores, como membros do Grupo Galpão, pois seria uma identidade instrumental para atingir fins desejáveis, tais como patrocínios, aceitação e legitimidade. Atrelado ao sentido da instrumentalidade, pressupõe-se o sentido da artificialidade dessa identidade, pois os próprios enunciadores revelam claramente os limites entre o que seria a representação autêntica da identidade do Grupo Galpão (grupo de atores que se concentra em viajar, fazer espetáculos e algumas oficinas) e o que seria a representação artificial da identidade do Galpão Entidade (grupo coeso de pessoas que realiza peças de teatro e projetos sociais). Nesse sentido, os discursos assumem novamente sentidos ambíguos, de afirmação de uma identidade única entre Galpão e Galpão Cine Horto perante a sociedade e de implicitamente delimitar os limites identitários autênticos no interior do Galpão Entidade.

\subsection{A estruturação do Grupo Galpão}

Ainda relacionado ao percurso semântico dos objetivos do Galpão, destaca-se o tema da estrutura do grupo, ou seja, como o grupo se articulou ao longo dos anos para atingir seus objetivos. Trata-se de um tema de relevância para identificar a racionalidade coletiva predominante, pois quanto mais prescritiva é a estrutura normativa de um sistema, mais ela guia o comportamento individual no sentido da conformação de papéis e, por conseguinte, menor é o espaço para atualização pessoal e expressão substantiva da identidade (RAMOS, 1981). No caso do Galpão, observa-se um aumento gradativo na estruturação do grupo.

"Ainda era uma estrutura em que todo mundo fazia as coisas aqui dentro, assim, o próprio grupo dava conta de solucionar o dia a dia, de produção, de..., enfim, de tudo que acarreta essa estrutura" (GG6).

"No começo, o grupo tinha uma estrutura em que os atores que tinham que fazer tudo, a produção, divulgação [...] aí depois é que com o tempo a estrutura foi crescendo e tal... Hoje, eu faço uma coordenação disso" (GG11).

Os dois trechos acima destacados abordam o tema da comparação entre a estrutura do início do grupo e como ela é hoje. GG6 indica de forma implícita tal sentido de comparação a partir do vocábulo ainda e dos verbos conjungados no pretérito imperfeito do indicativo, que sinalizam ações que foram habutais no passado. GG11, por sua vez, compara explicitamente a estrutura de antes e a de hoje e ilustra a mudança de papéis dos atores do Galpão com o próprio exemplo. O enunciador antigamente também desempenhava várias atividades para manutenção do grupo e, no momento em que o estudo foi realizado, ele apenas as coordenaria. Nos dois trechos, observa-se a personagem explícita dos atores do grupo, nas expressões todo mundo, próprio grupo e atores. Destaca-se também a personagem implícita do pessoal de apoio, que hoje existiria na estrutura do Galpão exclusivamente para dar suporte às atividades centrais do grupo. Essa personagem detém, portanto, a responsabilidade pelas atividades de manutenção estrutural do Galpão e teria aliviado a carga de trabalho para os atores. Contudo, a falta de destaque explícito e de menção aos nomes próprios desse grupo de personagens permite inferir que os enunciadores não atribuem grande importância a 
suas identidades individuais específicas para a construção da identidade coletiva do Grupo Galpão.

"As pessoas vão assumindo determinadas funções e tal e a gente tem um sistema de avaliação de desempenho [...]. E aí, em função disso, a gente faz avaliação do desempenho das pessoas e aí se define salário, né? Cachê dos espetáculos é igual pra todo mundo que atua, que tava no espetáculo, mas a gente tem uma diferenciação de salários em função dessa análise de desempenho, essa avaliação de desempenho" (GG11).

"A gente tem um caderninho de metas. Nós temos as nossas reuniões artísticas e as reuniões mais administrativas também aqui... que tem umas reuniões referentes à estrutura do grupo, que a gente até faz com o Pimenta, que é um mediador, é um cara que trabalha com a gente, pra gente conseguir conduzir bem os projetos. E temos essas anotações artísticas, que a gente volta e meia volta a elas, vê o que a gente cumpriu, o que a gente faz, então a gente sempre tem planos" (GG6).

"Essas reuniões de grupo são pautas mais difíceis de resolver, são decisões mais, decisões mais difíceis de se tomar, que aí convoca os 13 e esse mediador. Junto com isso, tem uma avaliação anual, de desempenho, vê o que cada um propôs no início do ano" (GG7).

Os trechos destacados representam a forma como os atores do grupo se estruturavam no momento em que a pesquisa foi realizada. A partir dos vocábulos funções, metas e planos, observa-se que há fixação de regras, metas e tarefas para os membros. Nesse aspecto, o Galpão parece reproduzir o modelo de equipes polivalentes para a produção artística, identificadas por Bendasolli et al. (2009). Contudo, GG11 e GG7 explicitam que a divisão funcional entre os atores se dá de forma espontânea e consentida por todos. Na fala de GG11, o uso do verbo assumir no gerúndio dá o sentido de naturalidade a esse processo. Ademais, GG7 emprega o verbo propor, que também conferiria o sentido de compromisso, individual e ativo, pelas atribuições. Após tal divisão de funções, a prática vigente do grupo no momento em que ele foi pesquisado era a de realizar periodicamente uma avaliação de desempenho. Essa expressão estabelece uma relação interdiscursiva com o discurso gerencial. A avaliação de desempenho é um conceito legítimo do campo discursivo da gestão de recursos humanos, notadamente em organizações econômicas. Contudo, tal expressão parece ter sido ressignificada ao ser utilizada no contexto do Grupo Galpão. Primeiramente, por não haver uma figura de autoridade centralizadora, que prescreve e impõe aos indivíduos seus cargos e papéis sociais. Em segundo lugar, por ser um processo conduzido pela personagem discursiva Pimenta, representada como um intermediador, que apenas facilitaria o processo avaliativo, realizado por todos coletivamente. A ideia da avaliação feita em conjunto por todos os membros está explícita no uso da primeira pessoa do plural e das expressões a gente e os 13. Portanto, apesar da prescrição mínima de normas, a avaliação de desempenho feita no Galpão não parece tornar seus membros agentes passivos do processo, nem eliminaria o espaço para iniciativas livres e substanciais dos indivíduos.

No entanto, simultaneamente, tal avaliação assume o sentido tradicional de instrumento de gestão ao ser utilizada como meio para distribuição dos rendimentos do grupo. Ao recompensar individualmente, diferenciando os membros e impondo o que é válido e merecedor de salário, o sistema avaliativo acaba por guiar de certa forma os comportamentos e por reduzir a liberdade dos indivíduos. Nesse sentido, mais uma vez, nota-se a existência de sentidos ambíguos nas práticas (discursivas) do grupo que, em última instância, remeteriam à tensão entre a necessidade de existência e a de transcendência a partir da produção artística.

"Eu acho, que essa é a grande diferença do Galpão que é um grupo que há 15 anos é patrocinado e conseguiu com isso uma organização e uma estrutura, que é organizado, estruturado. Justamente por isso a popularidade que o Galpão tem. O Galpão tem um público enorme em qualquer lugar que ele vai, isso também é uma grande diferença" (GG10).

"Muito, pensamos sempre muito na venda do espetáculo, né? Que tipo de perfil que tem aquele espetáculo, né? Que tipo... claro que o... a recepção do público é uma coisa que está sempre... muito presente na construção do espetáculo, sempre" (GG9).

A crescente estruturação do grupo direcionaria cada vez mais suas práticas ao atingimento de resultados positivos, entendidos como a boa aceitação do público. GG10 explicita inter-relações entre aspectos identitários do Galpão. $\mathrm{O}$ fato de o grupo possuir apoio de patrocinadores há anos e, com isso, poder estruturar-se, reforçou seu reconhecimento externo. Portanto, a possibilidade de estruturação possibilitou a afirmação da identidade do Galpão perante seu público, o que resulta em legitimidade e popularidade para o grupo. Infere-se, consequentemente, que isso trará os bons resultados, inclusive, reforçará as interações com o personagem patrocinador, pressupondo-se o relacionamento de troca típico do discurso do marketing cultural. GG9, por sua vez, explicita o pensamento voltado a resultados que emerge a partir da estrutura interna do Galpão. Novamente fica implícito que o sucesso do grupo reside na boa recepção de sua arte por parte do público. Nessas passagens, as práticas discursivas apontam para a representação de uma identidade instrumental do Grupo Galpão, como um grupo que deve articular-se para produzir 
espetáculos que vendam e que agradem ao público para, assim, conseguir manter a própria existência. $\mathrm{Na}$ expressão venda de espetáculo torna-se explícito o sentido de mercadoria ou de bem cultural da peça de teatro, que deverá ser comercializada. O espetáculo é o produto final do Galpão, seu meio para obter recursos e deveria ser pensado estrategicamente.

O tema da estruturação, em conjunto com o tema da obtenção de resultados, justifica uma série de práticas estratégicas do grupo, que sustenta sua identidade coletiva.

"A gente tem funcionado um pouco assim: a gente monta o espetáculo e este espetáculo fica em cartaz durante mais assim... às vezes, fica em cartaz dez anos, às vezes, 20. A gente é... é... como é que fala isso? É... é... a gente promove o espetáculo, assim, bastante, durante dois anos, o ano da montagem, mais um ano [...], já programando turnês nacionais e tal e pápá. E, depois, ele entra num ritmo, assim de repertório" (GG11).

"A gente tem espetáculos que são feitos dentro desse patrocínio da Petrobras e os espetáculos que a gente vende, né? Vende pra festivais, pra eventos, quer dizer, em princípio a gente vende pra qualquer situação, né?” (GG9).

“A peça do Galpão, ela não é, ela não é um trabalho para, não é só mais uma peça, é uma peça dentro de uma, dentro de uma empresa, dentro de uma coisa que já está estruturada e agora é aquela peça nova" (GG7).

Os três trechos destacados abordam o tema das estratégias do grupo. Implicitamente, o objetivo dessas estratégias seria a venda de espetáculos, que possibilitaria a manutenção da existência do grupo. GG11 descreve a estratégia do Galpão de manter por anos várias montagens, a mais recente foi promovida durante seus primeiros dois anos de apresentação. Nesse sentido, tal prática constrói a identidade do Galpão como um grupo de teatro de repertório. Implicitamente, tal identidade é reafirmada no discurso de GG9, que usa o vocábulo espetáculos, no plural, fazendo menção às várias peças que o grupo mantém como produtos a serem vendidos. GG7, por sua vez, representa a figura da peça do Galpão como um produto gerado por uma estrutura empresarial. Dessa forma, o sentido da peça nova torna-se secundário em relação ao sentido da manutenção da empresa. Nesse ponto observam-se, novamente, sentidos instrumentais nas práticas do Galpão, sendo a figura da peça representada como mercadoria.

\subsection{0 futuro do Grupo Galpão}

Para finalizar o percurso semântico dos objetivos do Grupo Galpão, destaca-se o tema dos planos do grupo.
"Fazer um espetáculo de sala, com estrutura menor, não precisa ser o elenco todo é... de muitas pessoas de... e aí a gente poder montar um outro desse tipo no outro ano, que não haver tanta produção, tanta... então a gente tá tentando mudar um pouquinho esse modus operandi atual nosso" (GG11).

"Acho que fazer um teatro mais despojado, mais simples, mais... uma coisa mais de sala, talvez que dependa menos de recursos técnicos. Essa é pelo menos a sugestão, a proposta que tá mais presente. [...] Eu acho que, além de ser bom como... artisticamente, pro trabalho dos atores, do grupo. Acho que economicamente pode ser interessante também, como uma coisa de ocupar um espaço que, normalmente, os espetáculos do Galpão têm mais dificuldade de ocupar, né? Às vezes, de se apresentar num lugar menor" (GG9).

O discurso predominante entre os membros entrevistados gira em torno do tema da mudança tática. Para garantia da sobrevivência do grupo, em tempos de imprevisibilidade e estabilidade, seria necessário criar táticas mais flexíveis e adaptativas. Tais práticas reformulariam a estrutura do Galpão na época da pesquisa, representada como grande e onerosa demais. Nesse sentido, reformular-se-ia também a própria identidade coletiva, o modus operandi do grupo. O sentido dessa mudança é permeado por aspectos instrumentais e substanciais. GG9 representa o plano de mudança tática como forma de expandir o escopo de atuação do grupo. Contudo, ao mesmo tempo, esse enunciador reconhece que a nova prática pode ser interessante para o desenvolvimento artístico dos membros.

Nesse sentido, o plano de realizar espetáculos menores seria uma tática de sobrevivência do grupo, alinhada ao objetivo estratégico da venda de espetáculos, mas, ao mesmo tempo, também representaria uma reformulação da estrutura interna do grupo, dando maior espaço para a expressão substancial das identidades. Seja qual for o sentido predominante que sustenta o discurso sobre os planos do grupo, a mudança das práticas alteraria a identidade coletiva do Galpão que estaria, portanto, aberta a modificações. A reformulação da identidade do grupo é um movimento que deve ser legitimado pelo público, mantendo-se, assim, o reconhecimento externo do Galpão como um grupo de teatro que merece ser apreciado. Nesse caso, observar-se-ia uma estratégia identitária externa (DUBAR, 2005).

\section{CONSIDERAÇÕES FINAIS}

A partir da análise exposta, é possível considerar que a identidade do Grupo Galpão foi construída a partir de estratégias e táticas que visavam à manutenção da sobrevivência do grupo e, ao mesmo tempo, à realização de objetivos éticos e estéticos comuns. Apesar de nem sempre haver consenso sobre 
os sentidos das práticas coletivas, demonstrando uma mistura de racionalidades e identidades individuais distintas, considera-se que a identidade do Grupo Galpão apresenta coesão interna, pois seus membros parecem aceitar os objetivos coletivos e certa prescrição mínima de funções e normas em suas práticas diárias. Tal conclusão pôde ser inferida por meio tanto das observações realizadas ao longo da pesquisa quanto dos discursos coletados, que apresentam um gênero discursivo com sentidos partilhados pelos membros, o que confere um padrão identitário às práticas discursivas do grupo. A legitimidade de sua estrutura, seus objetivos perante os membros e o reconhecimento externo de sua identidade garantem a manutenção identitária do grupo.

Mesmo se tratando de pessoas diferentes, os atores do Galpão conseguem compartilhar representações comuns, que alicerçam significados coletivos à identidade. Contudo, tendo em vista a instabilidade do mercado de bens culturais no qual o Galpão se insere, o desafio do grupo após quase 30 anos de existência seria reinventar suas práticas e, assim, sua identidade, porém mantendo laços identificatórios entre os membros e entre o público e o grupo. A estratégia de mudança identitária, vislumbrada para o futuro por meio da alteração nas práticas de formatação dos espetáculos, seria uma forma de contornar a situação em que o grupo se encontra: de refém das características identitárias construídas perante o público, o grupo encontrar-se-ia refém da própria identidade por necessitar realizar espetáculos caros e com grande estrutura devido à expectativa de seus espectadores.

Tendo em vista o caso estudado, pode-se considerar que o caminho da formalização estrutural, do aumento da prescrição normativa e da orientação a objetivos comuns parece ser necessário aos grupos que buscam sobrevivência no médio e no longo prazo dentro do mercado de bens culturais. Há pressões externas para a formalização, que atribuem identidades virtuais do tipo associações, Organizações Não Governamentais (ONGs), empresas, cooperativas, entre outras. Somente dessa forma as identidades coletivas obteriam reconhecimento e suporte de patrocinadores e outras fontes financiadoras. Por outro lado, pode haver pressões internas para a busca de um denominador comum, que mantenha o sentido do agrupamento e sustente a produção artística coletiva. O equilíbrio entre essas duas pressões parece ser um constante desafio aos integrantes de grupos artísticos. É preciso conciliar espaços de transcendência criativa e espaços de sobrevivência econômica. Ademais, é necessária a conciliação mínima de ideais éticos e/ou estéticos entre os membros, para que a produção conjunta de arte ocorra; e de práticas organizacionais, para que a interação com o mercado também aconteça.

A questão seria, nesse momento, a respeito da possibilidade de manutenção do equilíbrio entre sistemas valorativos distintos na produção artística coletiva. Tratar-se-ia de racionalidades diferenciadas que orientam práticas identitárias distintas. É possível verdadeiramente que uma identidade coletiva concilie ideais artísticos, calcados na busca pela transcendência humana, com a conformação ao sistema de compra e venda de espetáculos, influenciado por pressões econômicas e de mercado? Espera-se que as conclusões deste trabalho possam contribuir para futuras reflexões no campo de estudos sobre a construção da identidade no contexto das indústrias culturais (BENDASOLLI et al., 2009).

Aplicando-se o entendimento das identidades no sentido de práticas discursivas ao contexto das organizações, salienta-se a importância de estudar os indivíduos em relação aos níveis coletivos, pois, em diferentes enclaves da vida social, tornar-se-ia possível ao indivíduo exercer sua identidade diferentemente. Em contrapartida, rejeitando-se a concepção da identidade estática, defende-se também a ideia de que o indivíduo é capaz de exercer uma identidade autêntica em contextos pautados pela instrumentalidade, exercendo um papel dialético na metamorfose da própria identidade e também contribuindo para mudanças no contexto repressor em que se encontra (RAMOS, 1981; CIAMPA, 2005). Cabe ao pesquisador, portanto, identificar os grupos ou identidades coletivas que emergem no contexto das organizações e analisar a relação entre as racionalidades coletivas e individuais envolvidas, para que, ao final, seja desvendado o processo de construção das identidades em jogo.
ARENDT, H. A condição humana. Rio de Janeiro: Forense Universitária, 2004.

AVELAR, R. $O$ avesso da cena: notas sobre produção e gestão cultural. Belo Horizonte: Duo Editorial, 2008.

BAKHTIN, M. Estética da criação verbal. São Paulo: Martins Fontes, 1992.

BAUER, M.A.L.; MESQUITA, Z. As concepções de identidade e as relações entre indivíduos e organizações: um olhar sobre a realidade da agricultura ecológica. Revista de Administração Contemporânea Eletrônica (RAC-e), Curitiba, v.1, n.1, p.16-30, jan./abr. 2007. Disponível em: <www.anpad.org.br/rac-e>. Acesso em: 29 out. 2008.
BENDASOLLI, P.F.; WOOD JR., T.; KIRSCHBAUM, C.; CUNHA, M.P. Indústrias criativas: definição, limites e possibilidades. Revista de Administração de Empresas (RAE), São Paulo, v.49, n.1 p.10-18, jan./fev./mar. 2009.

BERGER, P.L.; LUCKMAN, T. A construção social da realidade: tratado de sociologia do conhecimento. 13.ed. Petrópolis: Vozes, 1998.

BRANDÃO, C.A.L. Grupo Galpão: uma história de risco e rito. 2.ed. Belo Horizonte: O Grupo, 2002.

CALDAS, M.P.; WOOD JR., T. Identidade organizacional. Revista de Administração de Empresas (RAE), São Paulo, v.37, n.1, p.6-17, jan./mar. 1997. 
CERTEAU, M. de. A invenção do cotidiano: artes de fazer. Petrópolis: Vozes, 1994.

CIAMPA, A.C. Estória do Severino e a história da Severina. São Paulo: Brasiliense, 2005.

DUARTE, R. A indústria cultural global e sua crítica. In: DUARTE, R.; FIGUEIREDO, V.; FREITAS, V.; KANGUSSU, I. (Org.). Kátharsis: reflexos de um conceito estético. Belo Horizonte: C/Arte, 2002. p.251-264.

DUBAR, C. A socialização: construção das identidades sociais e profissionais. São Paulo: Martins Fontes, 2005.

FAIRCLOUGH, N. Analysing discourse: textual analysis for social research. London: Routledge, 2003. [DOI: 10.1177/0957926503014001927].

FARIA, A.A.M.; LINHARES, P.T.F.S. O preço da passagem no discurso de uma empresa de ônibus. In: MACHADO, I.L. (Org.). Análises de discursos: sedução e persuasão. Belo Horizonte, NAPq Fale/UFMG, 1993. (Caderno de Pesquisa, 13).

FOUCAULT, M. A arqueologia do saber. Rio de Janeiro: Forense Universitária, 2007.
GLYNN, M.A. When cymbals become symbols: conflict over organizational identity within a Symphony Orchestra. Organization Science, v.11, n.3, Special Issue: Cultural Industries, p.285-298, May/June 2000.

HALL, S. A identidade cultura na pós-modernidade. 8.ed. Rio de Janeiro: DP\&A, 2003.

HORKHEIMER, M.; ADORNO, T. A indústria cultural - 0 iluminismo como mistificação das massas (1947). In:

ALMEIDA, J.M.B. (Org.). Indústria cultural e sociedade: Theodor Adorno. São Paulo: Paz e Terra, 2007.

MAINGUENEAU, D. Termos-chave da análise do discurso. Belo Horizonte: UFMG, 2000.

MANNHEIM, K. Ideologia e utopia. Rio de Janeiro: Guanabara, 1986.

MARCUSE, H. Sobre o caráter afirmativo da cultura (1937). In: MARCUSE, H. Cultura e psicanálise. São Paulo: Paz e Terra, 2001.

RAMOS, A.G. A nova ciência das organizações: uma reconstrução da riqueza das nações. Rio de Janeiro: FGV, 1981.

\section{The art of surviving together: studying the identity of the Grupo Galpão}

In this paper, we aimed at analyzing the construction process of Grupo Galpão's collective identity. Grupo Galpão is a group of theater actors from Belo Horizonte. It was founded twenty nine years ago. Our goal was to study identity related to the context of cultural industry. In order to perform it, we started from individual level to comprehend collectively shared meanings, basically, considering the group's objectives and structure. Since individual identity is built by discursive practices and since discursive practices are always related to sociolinguistic structures e discursive genres, individual identity is revealed in certain context and in relation to other identities, individual or collective ones. In this research, we understand that interaction spaces defined by collective identities may limit the expression of individual identities. However, occasionally, an individual can be able to transform him/herself and actively transform spaces where domination relationships take place. In order to get inside Grupo Galpão's quotidian reality, the researcher collect data during twelve months, including observations and in depth interviews. By the end, we highlight Grupo Galpão's identitary aspects that demonstrate the group's current stability. On the other hand, results also reveal some tension between the rationality of the cultural goods market and the rationality inherent of authentic arts production.

Keywords: identity, discursive practices, collective identity, theater group.

\section{El arte de (sobre)vivir colectivamente: un estudio de la identidad del Grupo Galpão}

El objetivo de este artículo fue analizar el proceso de construcción de la identidad colectiva del Grupo Galpão, un grupo de actores de teatro fundado hace veinte y nueve años y que se queda en Belo Horizonte. Se abordó el tema de la identidad en relación al contexto de la industria cultural. Para estudiar la identidad, se partió del nivel individual para comprenderse los significados colectivamente compartidos, en relación a los objetivos y a la estructura del grupo. Siendo la identidad individual construida a partir de las prácticas discursivas y siendo estas siempre relacionadas a las estructuras sociolinguísticas y a los géneros discursivos, la identidad individual es revelada en un contexto y en relación con las otras identidades, individuales o colectivas. Se comprende, en esta pesquisa, que los espacios de interacción delimitados por las identidades colectivas traen límites para la expresión de las identidades individuales. Ocasionalmente, el individuo lograría transformarse y transformar activamente los espacios que le imponen relaciones de dominación. Para penetrar en la realidad diaria del Grupo Galpão, fueron realizadas observaciones y entrevistas, las cuales fueron tratadas por el análisis del discurso. Al fin de la pesquisa, fueron evidenciados aspectos de la identidad del Grupo Galpão, que comprueban la estabilidad del grupo, pero, revelan tensiones entre la racionalidad del mercado de bienes culturales y la racionalidad inherente a la producción artística auténtica.

Palabras clave: identidad, práctica discursiva, identidad colectiva, grupo de teatro. 